\title{
Heritage Language Vitality among University Students in Malaysia
}

\author{
Paolo Coluzzi \\ paolo.coluzzi@um.edu.my \\ University of Malaya
}

\begin{abstract}
Malaysia is a multi-ethnic and multilingual country where over 130 languages are spoken by a population of around 32 million people. In spite of such diversity, only one language is official: Malay. English and Mandarin are very widespread, and in many cases, they are slowly replacing the local ethnic languages. This paper attempts to gauge the extent of language shift and displacement of the family heritage language (the language(s) spoken by parents or grandparents) among 189 students from the Faculty of Languages and Linguistics at the University of Malaya, Kuala Lumpur. The ethnolinguistic vitality of these languages within this particular population was determined through a sociolinguistic survey on language use and attitudes. The article closes with some thoughts on the factors that might explain the results obtained, and what could be done to improve the situation.
\end{abstract}

Keywords: Dialects, language shift, language vitality, Malaysia, minority languages 


\section{Introduction}

Malaysia is a multi-ethnic and multilingual country of around 32 million people, where over 130 languages are spoken (Eberhard, Simons, \& Fennig, 2019) by a population made up mainly of Malays (54.6\%), other Bumiputras (12.8\%), ${ }^{1}$ Chinese (24.6\%), Indians, particularly Tamil (7.3\%), and other unlisted ethnic groups $(0.7 \%)$ (Saw, 2015). In spite of such diversity, only one language is official, namely Malay, whereas English and Mandarin are very widespread and in many cases they are slowly replacing the local ethnic languages (Coluzzi, 2017). It can be said that nearly all Malaysians are bilingual or multilingual. In some cases, they only use two varieties, for example a local Malay dialect and some form of standard Malay; in many cases, Malaysians can speak three or more languages and/or dialects, for example a Chinese 'dialect', Mandarin, Malay, and English. This diversity seems to be in decline, particularly among young educated Malaysians who have expanded the usage of mainstream languages, thus replacing the languages of their parents and grandparents, as summarized in the following patterns:

1. Mandarin and English in the case of ethnic Chinese, displacing Chinese dialects;

2. Standard Malay and English in the case of ethnic Malays, replacing Malay dialects;

3. Tamil and English in the case of the ethnic Indians, replacing other Indian languages.

A sociolinguistic survey on language use and attitudes of a sample of students from the Faculty of Languages and Linguistics at the University of Malaya, Kuala Lumpur, was carried out with the goal of gauging the extent of language shift and displacement of the family heritage language. The respondents consisted of all the students in the Department of Asian and European Languages. A heritage language refers to the main language in the family's linguistic repertoire, which has been passed down from one generation to the next within the family and is still spoken at least by the parents and/or grandparents. This paper attempts to determine the degree of ethnolinguistic vitality of these languages among a sample of educated young Malaysians, namely the respondents, and to assess their attitudes towards their heritage languages by analyzing their responses concerning language knowledge (the languages/dialects they know), use, and attitudes. More specifically, the respondents' linguistic repertoire was compared against that of their parents and grandparents, based on responses regarding the languages they speak and understand, the

\footnotetext{
${ }^{1}$ The term "Bumiputra" refers to the ethnic groups considered to be the original inhabitants of Malaysia. In addition to the Malays, these include the various tribal groups of Borneo and the aboriginals of the peninsula, known as Orang Asli, plus other smaller groups.
} 
declared first language(s) of the respondents, and the language(s) used within the family. Even though the results may not be generalizable to the whole country, they will nevertheless give an idea of the state of the heritage languages spoken in Malaysia among educated young adults.

\section{Language Vitality in Malaysia}

Our knowledge of the degree of endangerment of most minority languages in Malaysia is patchy at present as not much research has been carried out to determine their level of vitality. Research that has looked at ethnolinguistic vitality of minority languages in Malaysia in a more or less direct way includes: Alias, 2014 (Semai); Alias and Salasiah, 2015 (Semang Kensiu); Babu, 2016 (Telugu); Benjamin, 2004 (Orang Asli languages); Bishop, 2001 (Kensiu); Coluzzi, Riget, and Kitade, 2018 (Baba Malay); Coluzzi, Riget, and Wang, 2013, 2017 (Bidayuh, Mah Meri); Coluzzi, 2017 (Bidayuh, Mah Meri and other minority languages in Malaysia); David, 2006 (Sindhi); David and Faridah, 1999 (Malacca Portuguese or Cristang); David, Naji, and Kaur, 2003 (Punjabi); David and McLellan, 2014 (Bidayuh, Malayalee, Sindhi, Kelantanese Peranakan Hokkien); Dealwis, 2008 (Bidayuh); Kamila, 2005 (Mah Meri); Low, Nicholas, and Wales, 2010 (Mandarin, Hokkien and other Chinese varieties in Penang); Nasuha, 2016 (Kelantanese); Norazuna, 2010 (Bidayuh); Noriah and Nor Hashimah, 2012 (Sihan); Pillai, Soh, and Kajita, 2014 (Malacca Portuguese); Roshidah, Kamila, and Asmah, 2015 (various Orang Asli languages in Gerik, Perak); Smith, 2010 (Kadazandusun, Iranun, Iban, Semai); Ting and Ling, 2013 (various indigenous languages in Sarawak); Ting and Tham, 2014 (Kadazandusun); Wang, 2010 (various Chinese varieties in Kuala Lumpur); Wang and Chong, 2011 (various Chinese varieties in Kuala Lumpur); and Wazir, 2001 (various Orang Asli languages).

This research aims to make a further contribution to our current knowledge on which languages in Malaysia can be deemed as relatively safe, and which are endangered and in need of urgent measures of revitalization. A summary of the degree of vitality of a number of heritage languages spoken in Malaysia based on the research carried out to date is provided by Coluzzi (2017), whose main results (updated in Coluzzi et al, 2018) can be seen in Table 1. These are based on the measurement tool of ethnolinguistic vitality known as EGIDS (Expanded Graded Intergenerational Disruption Scale - see Lewis \& Simons, 2010), derived from Fishman (1991) with: 
1. the levels of high to low vitality shown in the first column (from 0 to 10 with two sublevels a' and 'b' for levels 6 and 8),

2. the corresponding label in the second column, and

3. a list of Malaysian languages that according to EGIDS diagnostics correspond for each level.

When the level varies according to the speech community and geographical location, the same language has been classified under more than one label.

Table 1: EGIDS level for Malaysian languages (Coluzzi et al, 2018)

\begin{tabular}{lll}
\hline Level & Label & Languages \\
\hline 0 & International & English, Mandarin, (Arabic) \\
1 & National & Standard Malay \\
2 & Provincial & No languages at this level in Malaysia \\
3 & Wider communication & Iban, Kelantanese, Cantonese, Hokkien \\
4 & Educational & Tamil, Kadazandusun, Iban, Thai \\
5 & Developing & Iban, Telugu \\
$6 \mathrm{a}$ & Vigorous & Bidayuh (and other indigenous languages in Borneo), Mah Meri, Temiar, \\
& & Semai (and other indigenous languages in peninsular Malaysia), \\
& & Cantonese, Hokkien \\
$6 \mathrm{~b}$ & Threatened & Kadazandusun, Cantonese, Hokkien, Punjabi, Baba Malay \\
7 & Shifting & Bidayuh (outside the Bidayuh Belt), Hakka, Teochew, Hokchiu, Hainanese \\
& & (and other Chinese 'dialects'), Baba Malay \\
$8 \mathrm{a}$ & Moribund & Kristang, Sindhi \\
$8 \mathrm{~b}$ & Nearly extinct & None \\
9 & Dormant & Orang Kanak \\
10 & Extinct & Wila' (Lowland Semang), Ple-Temer \\
\hline
\end{tabular}

As will be shown, some of these languages and many more besides, are spoken and/or understood by the respondents in the current study, even though they are used less frequently than in the past. 


\section{Methodology}

Data were collected via a questionnaire on language use and attitudes from 189 students taking a degree in foreign languages at the University of Malaya (Kuala Lumpur, Malaysia). ${ }^{2}$ The University of Malaya is the oldest university in Malaysia, attended by students of all ethnic groups, coming from all over the country and different social backgrounds. The questionnaire consisted of 25 questions which included personal details (name, gender, ethnic group, age, course taken, father's and mother's ethnic groups, first language), language knowledge (languages spoken, languages not spoken but understood, languages spoken by father, mother, and grandparents from both sides), language use (language spoken most fluently, language normally spoken within the family, language normally spoken with various relatives plus partners, and with classmates) and language attitudes (whether the respondents agreed that minority languages and dialects in Malaysia should be officially protected, whether there should be radio programmes or publications in these languages, and whether these languages should be taught in school). For this research, however, only the responses regarding the languages spoken and understood by the respondents, the languages spoken by parents and grandparents, the respondents' first language and the language(s) that is/are normally used within the family were looked at, in addition to responses concerning the official status for minority languages and dialects as well as teaching them at school. In fact, these questions were deemed sufficient to gauge the level of language shift on one hand, and the attitudes of the respondents on the other. When distributing the questionnaires, it was made very clear to the students that they had to take any language variety into consideration, including those that are considered 'dialects', as long as they (or their families) could communicate in them, even imperfectly.

The languages spoken by the respondents and those spoken by their parents and/or grandparents were compared. The heritage languages (those spoken by both students and at least one of their parents and/or grandparents) that the respondents declared they could speak or at least understand were noted, while the students who did not report speaking any of the family's heritage languages (i.e. those who said they could only speak Malay, Mandarin or English) were deemed to have lost them (even though some respondents declared they could understand some of them,

\footnotetext{
${ }^{2}$ I would like to thank my colleagues Rie Kitade, Wai Sheng Woo, Musaev Talaibek, Jean Severy, Kamil Ghazali, Gian Piero Taricco, Omar Colombo, Fabio Provenzano, Eugenia Conde Noguerol, Caning Jaramillo Rengifo, Rozita Che Omar, Adelina Danailova, and Charity Lee for allowing me to administer the questionnaires during their classes.
} 
which is indicative of a lack of intergenerational language transmission). The responses to other questions helped to confirm and clarify this, and to show whether the respondents had positive attitudes in general towards the 'small' languages spoken in Malaysia.

\section{Results}

The results obtained can be seen in Table 2 .

Table 2: Results of the survey

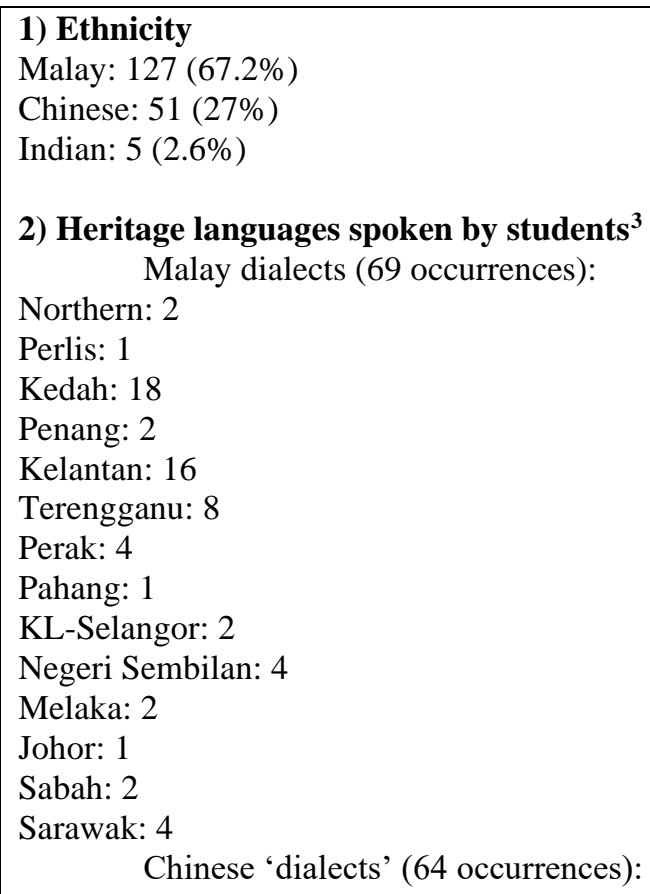

\footnotetext{
${ }^{3}$ Some students can speak more than one heritage language, typically the one spoken in the mother's family and that spoken in the father's family. Some Chinese students can also speak a local Chinese "lingua franca", such as Cantonese in Kuala Lumpur. However, if that language was not spoken by the parents and/or grandparents it was not counted as a heritage language (see section 4 ).
} 


\section{3) Heritage languages understood by students but not spoken: \\ Malay dialects (14 occurrences):}

Northern: 1

Kedah: 1

Penang: 1

Kelantan: 5

Perak: 1

Negeri Sembilan: 3

Melaka: 1

Sarawak: 1

Hokkien: 17

Chinese 'dialects' (40 occurrences):

Cantonese: 6

Hakka: 13

Teochew: 1

Foochow: 1

Hainan: 2

Tamil: 2

Indian languages (2 occurrences):

Kadazan: 1

Bornean languages (3 occurrences):

Dusun: 1

Iranun: 1

Others:

Javanese (6)

Punjabi (1)

Thai (2)

Indonesian (1)

Banjar (2)

Total: 71 occurrences

\section{4) Students' first languages:}

Standard Malay: 99

Other Malay 'dialects': 35 (Northern dialect: 1, Kedah: 8, Kelantan: 11, Terengganu: 4, Perak: 2, Negeri

Sembilan: 2, Johor-Riau: 2, Sarawak: 3, Sabah: 2)

Mandarin: 44

Hokkien: 1

Cantonese: 8

Other Chinese 'dialects': 1 (Foochow)

Tamil: 4

English: 8

Others: 7 (Kadazan, Javanese, Minagkabau, Indonesian, Dusun (2), Hindi)

5) Number of students who speak at least one heritage language as a first language:

$56(29.6 \%)$

6) Languages normally used within the family:

Standard Malay: 90

Other Malay 'dialects': 60 (Northern dialect: 4, Perlis: 1, Kedah: 9, Penang: 2, Kelantan: 13, Terengganu: 7,

Perak: 6, KL: 1, Negeri Sembilan: 4, Melaka: 2, Johor-Riau: 2, Sabah: 2, Sarawak: 4, Non-standard Malay: 3)

Mandarin: 45

Hokkien: 9

Cantonese: 12

Other Chinese 'dialects': 9 (Hakka: 6, Teochew: 2, Foochow: 1) 


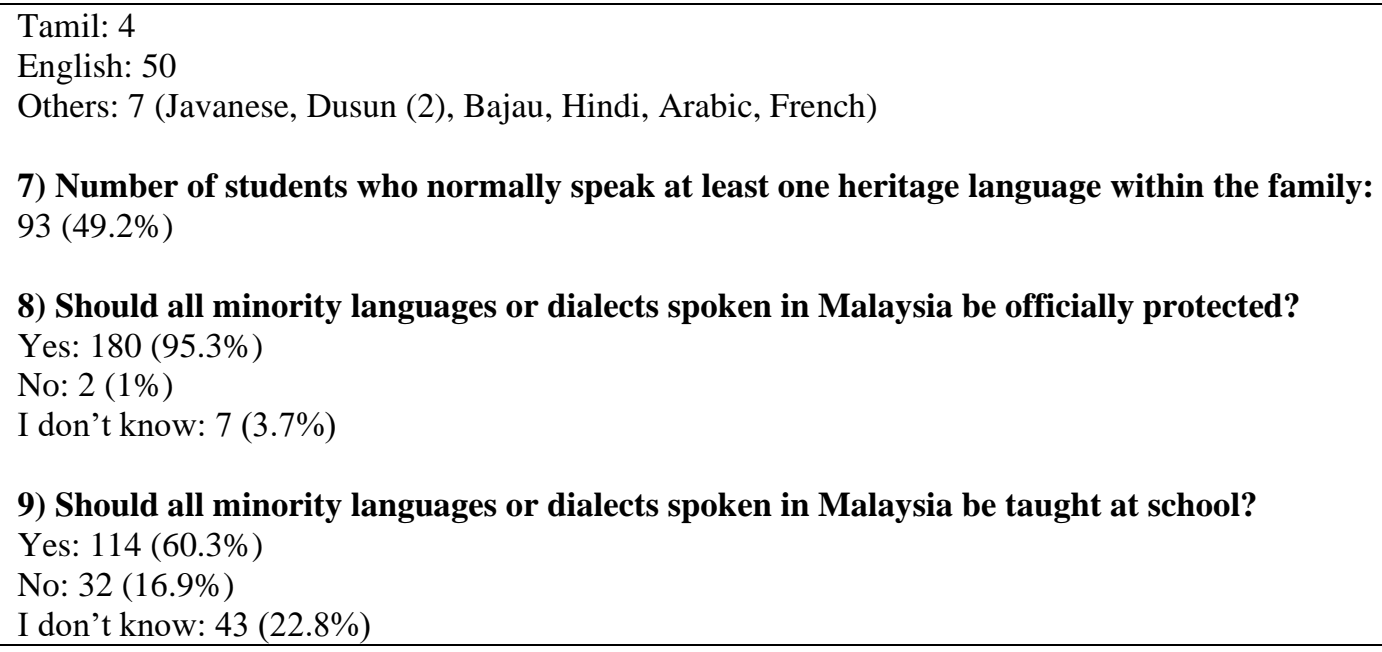

As can be observed in Table 2, the language varieties spoken or understood have been subdivided into Malay dialects, Chinese dialects, Indian languages (only those historically present in Malaysia, hence in our sample only Tamil), Bornean languages, and other languages (not classifiable under the previous categories, even though some, such as Minagkabau or Javanese, might be also included among the minority languages spoken in Malaysia, as many of their speakers and their ancestors were born in the country). Some of the names used for these language varieties, however, need explanation.

As far as the Malay varieties are concerned, it is widely believed that Peninsular Malaysia has nine main dialect groups, whereas Malaysian Borneo has only two (Asmah, 2004). They are: (1) Peninsular Malay varieties: Kedah, Kelantan, Terengganu, Perak, Pahang, Johor, Negeri Sembilan, Melaka, Selangor; (2) Borneo Malay varieties: Sarawak, Sabah. On top of these, minor Malay varieties should be added, such as Baba, Chitty (spoken respectively by Peranakan Chinese and Indians in Melaka), Temuan, Jakun, Orang Kanaq, Orang Kuala, Orang Selatar (spoken by Orang Asli groups), Brunei and Kedayan (spoken in Borneo) (Asmah, 2004). The isoglosses delimiting the areas where these 'regional' dialects are spoken do not coincide exactly with the borders of the regions whose names they bear. In fact, Kedah Malay is reportedly spoken in Perlis, Penang and northern Perak as well as Kedah, whereas Kelantan Malay is also spoken in parts of neighbouring Kedah, Terengganu and Pahang (Asmah, 2004).

Malay dialects have not been standardized and are almost exclusively used in oral form, exhibiting large internal variation which most of the students may not be aware of and have little knowledge about. Therefore, for this paper the names indicated by the respondents were accepted, 
even when they should perhaps be included in a dialectal area that bears the name of a different neighbouring region. What is significant is rather the perception of the students and the varieties they somehow identify with. I have also retained the term 'Northern dialect' used by some respondents, which would probably refer to the Kedah or other neighbouring dialects. As a matter of fact, some of these dialects do not differ much from neighbouring varieties, with the differences being mainly phonological and lexical, and that is the reason some students have listed a few Malay varieties among the languages they could understand but not speak. On the whole, northern varieties, and specifically Kelantan Malay, seem to show the greatest divergence from standard Malay, whose historical roots could be traced to the southern variety of Johor Malay.

As for the other languages mentioned by the respondents, there do not seem to be any problem with respect to their identification, as they are all, whether Sino-Tibetan, Dravidian or Austronesian, abstand languages with recognized and accepted names, some of which have standard versions.

Another point that should be made here is that a certain number of students seem to have learned the local language of the place of current or past residence. This applies particularly to Cantonese (spoken, for example, by most Chinese in Kuala Lumpur, with a strong presence on television as well), and Kelantan Malay. In these cases the minority variety has not been considered if it did not feature among the languages spoken by the parents or grandparents, even though we are aware of the possibility that in some cases these languages may become family languages and be passed down to the next generation (see note 3 ).

\section{Results and Discussion}

Even though 28 heritage languages are spoken by 119 respondents (63\%), and 23 are understood even if not spoken, the data collected may not be as optimistic in terms of heritage language maintenance as it may appear. In fact, only in 101 cases are the heritage languages normally spoken within the family (which may or may not be in conjunction with other 'big' languages such as standard Malay, English, or Mandarin) by 93 respondents (49.2\%), and in as few as 56 cases $(29.6 \%)$ are the heritage languages declared to be the respondents' first languages. The great majority of students have standard Malay (99), Mandarin (44), or English (8) as their first languages (even though these may have been learnt together with a minority language or 'dialect'), 
and use them within the family (standard Malay: 90, Mandarin: 45, English: 50). ${ }^{4}$ An educated guess is that only the students who have a heritage language as their first language may decide to pass it on to the next generation (and probably only one of them if they have more than one heritage first language), depending obviously on various factors, including the prestige and spread of the language, where they reside, their partners' ethnicity, and the languages they are able to speak. This means that as few as 56 students, that is a little less than one third of the total, may pass down one or more of their heritage languages to their children. However, based on the author's previous research (Coluzzi, 2010; Coluzzi et al., 2013, 2017), it is most likely that only the respondents who end up marrying a partner speaking the same heritage language and/or living in areas where the heritage language is widely spoken may retain it. Considering the present high levels of mobility in the country, only a small part of these 56 students will probably keep intergenerational transmission going, which does not bode well for Malaysia's linguistic diversity.

As for the heritage languages still spoken, the most vital ones among the ethnic Malay students appear to be the northern Malay varieties: Kedah (18), Kelantan (16), and Terengganu Malay (8). On the other hand, among the ethnic Chinese students the most vital Chinese varieties are Cantonese (30) and Hokkien (17), followed by Hakka (10). As far as the heritage languages understood but not spoken are concerned, the first would be Kelantan Malay among the Malays, and Hokkien (17) and Hakka (13), followed by Cantonese (6) among the Chinese. Tamil seems to be the most vital heritage language, as all five Indian respondents declared they can speak it. This is probably due to the fact that Malaysia has national-type primary schools where Tamil is used as a medium of instruction, whereas the Chinese schools use Mandarin, a language that was hardly spoken natively by any Chinese in Malaysia until the 1920s (Lee, 2010; Wang, 2010). ${ }^{5}$

If we now look at the respondents' first languages, among the Malay respondents, Kelantan Malay counts as mother tongue for 10, Kedah Malay for 8, and Terengganu Malay for 4, a ranking that corresponds exactly to the order of the most spoken languages. Likewise, as far as the Chinese respondents are concerned, the most spoken first language is Cantonese ( 8 respondents).

If we finally look at the most spoken heritage languages within the family, for the Malays they are again the northern varieties: Kelantan Malay (13), Kedah Malay (9), Terengganu Malay

\footnotetext{
${ }^{4}$ As can be observed, English is used within the family even by many respondents who do not speak it as a first language.

${ }^{5}$ Obviously five Indian students are not enough to generalize on the vitality of their heritage language. However, personal experience and observation seem to confirm the high vitality of Tamil in Malaysia.
} 
(7), Northern dialects (4), and Perak Malay (6). In a similar fashion, for the Chinese the family languages are Cantonese (12), Hokkien (9), and Hakka (6). As the University of Malaya accepts students from all over the country (however, with a lower number from Borneo, partly due to costs owing to the travel distance), from these data we may conclude that the Malay northern varieties, Cantonese and Hokkien (followed by Hakka), and Tamil are the most vital heritage languages in our sample. These are all widely spoken languages that bear good levels of prestige, particularly Kelantan Malay (see Nasuha, 2016), Cantonese (the official language of Macao and Hong Kong, widely used in films, videos, and songs), and Tamil (likewise the official language of Tamil Nadu and Puducherry in India, and Singapore, and widely used in films, videos, and songs). It is interesting to notice that Kelantan Malay, Cantonese, and Hokkien are among the minority languages and dialects that are not considered threatened according to the research carried out so far (see Table 1). Even though specific research on the vitality of Tamil has not been undertaken to date, it can be safely assumed that this language, too, is still to be considered safe in Malaysia (see Table 1).

Therefore, even though some heritage languages seem to be spoken more than others (and are therefore more vital), considering that nearly all the respondents' parents and/or grandparents can/could speak at least one heritage language, often more than one, a language shift towards majority languages is clearly evident. In fact, the 70 students (37\%) who have 'lost' their heritage language, can only speak Malay, Mandarin, and/or English. ${ }^{6}$ As a matter of fact, in as many as 151 cases $\left(79.8 \%\right.$ ) a majority language is the first language of the respondents, ${ }^{7}$ and in many more cases (185, or 97.8\%) Malay, Mandarin, and/or English (on their own or together with other languages in the repertoire) are used within the family. ${ }^{8}$ As was shown above, English is the second most spoken language in the family domain (50 respondents) after Malay (90 respondents) and immediately before Mandarin (45 respondents).

\footnotetext{
${ }^{6}$ It must be highlighted here that all three languages are spoken in their more standard or colloquial varieties: Malay can be more or less close to the standard or present some colloquial (street slang) or regional features. The Mandarin spoken by Chinese Malaysian also presents various registers and some features developed in contact with other Chinese varieties that differentiate it from the Mandarin spoken in China. English, on the other hand, can be very close to the British standard (perhaps with features from American or Australian English) or, more often than not, presents clear local features that were developed in contact with the local languages.

${ }^{7}$ English: 8 + Standard Malay: 99 + Mandarin: 44. However, some of the respondents declaring to have English, standard Malay or Mandarin as their first language may also have another first language that could be a heritage one. ${ }^{8}$ English: 50 + Standard Malay 90 + Mandarin: 45.
} 
Finally, language attitudes towards Malaysian heritage languages seem to be very positive, since as many as 180 respondents $(95.3 \%)$ think all minority languages and dialects in Malaysia should be protected by law, while 114 respondents $(60.3 \%)$ believe these languages should be taught in school. The idea of burdening the school curriculum with other languages, however, put some of the respondents off, as 32 (16.9\%) disagree with the idea of having these languages taught at school, while as many as $43(22.8 \%)$ were undecided. There is obviously a difference between theoretical stance and actual implementation, i.e. it is one thing to show an interest in these languages being somehow retained, and quite another thing to commit one's time and energy to their maintenance.

\section{Conclusions}

Even though a similar survey carried out among youths in other parts of Malaysia or in other universities may provide different results, considering the overall situation of minority languages and dialects in Malaysia attested by previous research (for a summary, see Coluzzi, 2017), we may safely affirm that the vast majority of the heritage languages looked at in this research are more or less endangered. Some of these languages might show higher levels of ethnolinguistic vitality in some of the areas where they are still spoken by the majority of the local population (see for example Coluzzi et al, 2013, 2017), or enjoy higher levels of prestige because of official status in other countries, copious literature, use in the mass media, etc. In addition, young people with lower levels of education residing outside urban areas may be retaining their heritage languages more than those who have decided to leave their villages or provincial towns and study at one of the national universities. On the other hand, students at private universities may show different patterns of language maintenance and/or shift, possibly with a higher rate of first language speakers of 'stronger' languages such as English, Mandarin, or Standard Malay. In any case, official statistics show that in 2017 as many as $42 \%$ of Malaysians were enrolled in tertiary education (UNESCO Institute for Statistics, 2018), which means that a high percentage of Malaysian youth may be losing their family heritage language in a similar fashion as shown in this survey. Therefore it could be safely stated that most of Malaysia's heritage languages are endangered, and while some may be maintained for some time (for example, the ones that feature more speakers in this research), others are bound to shrink and disappear in the not-too-distant future, unless something is done to maintain them. As most of these languages are not normally used in the written form 
and do not seem to provide any direct cultural and economic advantages to their speakers, they are being abandoned in favour of Malay, Mandarin, and/or English, i.e., the 'big' languages that are perceived as offering the best job and study opportunities. As has been shown, over one third of the respondents have lost their heritage languages altogether, with only some being able to understand them to a certain extent. It is only if these 'small' languages could be seen as providing some sort of benefits that they may survive in Malaysia. This could be achieved by providing them with an official status as minority or regional languages, and by carrying out some strategies of languages planning (which seems to be what the majority of the respondents would like to see). However, considering the strong nationalism and protectionism for Malay, and the trends towards globalization that favour English and the expansion of Mandarin as both a unifying language for the Chinese and an increasingly prominent international language, the chances of Malaysian 'small' languages surviving in the distant future appear to be unfortunately very slim.

\section{References}

Alias Abd Ghani. (2015). The teaching of indigenous Orang Asli languages in peninsular Malaysia. Procedia - Social and Behavioural Sciences, 208, 253-262.

Alias Abd Ghani \& Salasiah Che Lah (2015). The Semang Kensiu Orang Asli of Lubuk Legong, Baling: Their languages and cultural endangerment. Procedia - Social and Behavioural Sciences, 208, 21-30.

Asmah Haji Omar (2004). Regional varieties of Malay. In Asmah Haji Omar (Ed.), Encyclopedia of Malaysia: Languages and literature (Vol. 9) (pp. 26-27). Singapore: Editions Didier Millet.

Babu, K. (2016). Language shift and maintenance among the Telugu community in the Klang Valley (Unpublished master's dissertation). University of Malaya, Malaysia.

Benjamin, G. (2004). Aslian languages. In Asmah Haji Omar (Ed.), Encyclopedia of Malaysia: Languages and literature (Vol. 9) (pp. 46-47). Singapore: Editions Didier Millet.

Bishop, N. M. (2001). Sociolinguistic aspects of Northern Aslian languages: A case study of Kensiw (Kensiu) [Baansakai, Yala, Thailand]. In Wazir Jahan Karim \& Razha Rashid (Eds.), Minority cultures of Peninsular Malaysia: Survival of indigenous heritage (pp. 83-99). Penang, Malaysia: The Academy of Social Sciences. 
Coluzzi, P. (2010). Endangered languages in Borneo: A survey among the Iban and Murut (Lun Bawang) in Temburong, Brunei. Oceanic Linguistics, 49(1), 119-143.

Coluzzi, P. (2017). The vitality of minority languages in Malaysia. Oceanic Linguistics, 56(1), 210-225.

Coluzzi, P., Riget, P. N., \& Wang, X. (2013). Language vitality among the Bidayuh of Sarawak (East Malaysia). Oceanic Linguistics, 52(2), 375-395.

Coluzzi, P., Riget, P. N., \& Wang, X.. (2017). Language vitality among the Orang Asli of Malaysia: The case of the Mah Meri on Telo' Gunjeng (Carey Island, Selangor). International Journal of the Sociology of Language, 244, 137-161.

Coluzzi, P., Riget, P, N., \& Kitade, R. (2018). Is the Baba Nyonya a doomed community? A preliminary study on the vitality of Baba Malay in Melaka (Malaysia). Grazer Linguistische Studien, 89, 111-139.

David, M. K. (2006). Language choice in Sindhi families. In M. K. David (Ed.), Language choices and discourses of Malaysian families (pp. 3-21). Petaling Jaya, Malaysia: SIRD.

David, M. K., \& Faridah Noor Mohd (1999). Language maintenance or language shift in the Portuguese settlement of Malacca in Malaysia? Migracijske Teme, 15(4), 465-81.

David, M. K., \& McLellan, J. (2014). Political, educational and socioeconomic motivations for language shift in multilingual Malaysia. In P. Sercombe \& R. Tupas (Eds.), Language, education and nation-building: Assimilation and shift in Southeast Asia (pp. 131-147). Basingstoke, England: Palgrave Macmillan.

David, M. K., Naji, I. M. H., \& Kaur, S. (2003). Language maintenance or language shift among the Punjabi Sikh community in Malaysia? International Journal of the Sociology of Language, 161, 1-24.

Dealwis, C. (2008). Language choice among the Dayak Bidayuh undergraduates (Unpublished doctoral thesis). University of Malaya, Malaysia.

Eberhard, D. M., Simons, G. F., \& Fennig, C. D. (Eds.). (2019). Ethnologue: Languages of the world (22nd edn.). Dallas: SIL International. Online version: http://www.ethnologue.com.

Fishman, J. (1991). Reversing language shift. Clevedon, England: Multilingual Matters Ltd.

Kamila Ghazali (2005). Domains of language use and attitudes: Mah Meri. In D. T. Dayag \& J. S. Quakenbush (Eds.), Linguistics and language education in the Philippines and beyond (pp. 573-591). Manila, Philippines: De la Salle University Press. 
Lee, H. G. (2010). The limits of Malay educational and language hegemony. Southeast Asian Affairs, 2010, 180-197.

Lewis, P., \& Simons, G. (2010). Assessing endangerment: Expanding Fishman's GIDS. Revue Roumaine de Linguistique/Romanian Review of Linguistics 2. Retrieved from http://www.lingv.ro/resources/scm_images/RRL-02-2010-Lewis.pdf

Low, H. M., Nicholas, H., \& Wales, R. (2010). A sociolinguistic profile of 100 mothers from middle to upper-middle socio-economic backgrounds in Penang-Chinese community: What languages do they speak at home with their children? Journal of Multilingual and Multicultural Development, 31(6), 569-584.

Nasuha Suhaili (2016). Language use among Malays in Kelantan (Unpublished master's dissertation). University of Malaya, Malaysia.

Norazuna Norahim (2010). Language choice of Bidayuh graduates in Kuching-Samarahan Division (Unpublished doctoral thesis). University of Malaya, Malaysia.

Noriah Mohamad, \& Nor Hashimah Hashim (2012). Language vitality of the Sihan community in Sarawak, Malaysia. Kemanusiaan, 19(1), 59-86.

Pillai, S., Soh, W.-Y., \& Kajita, A. (2014). Family language policy and heritage language maintenance of Malacca Portuguese creole. Language Communication, 37, 75-85.

Roshidah Hassan, Kamila Ghazali, \& Asmah Haji Omar (2015). Vitality of the Orang Asli languages in Gerik, Perak. Oceanic Linguistics, 54(2), 494-508.

Saw, S. H. (2015). The population of Malaysia. Singapore: Institute of Southeast Asian Studies Publishing.

Smith, K. (2010). Minority language education in Malaysia: Four ethnic communities' experiences. International Journal of Bilingual Education and Bilingualism, 6(1), 52-65.

Ting, S. H., \& Ling, T. Y. (2013). Language use and sustainability status of indigenous languages in Sarawak, Malaysia. Journal of Multilingual and Multicultural Development, 34(1), 7793.

Ting, S. H., \& Tham, F. L. (2014). Vitality of Kadazandusun language in Sabah, Malaysia. AsiaPacific Studies, 1(1), 44-57.

UNESCO Institute for Statistics (UIS) (2018). Retrieved from http://uis.unesco.org/country/MY 
Wang, X. (2010). The sociolinguistic realignment in the Chinese community in Kuala Lumpur: Past, present and future. Journal of Multilingual and Multicultural Development, 3(5), 479489.

Wang, X., \& Chong, S. L. (2011). A hierarchical model for language maintenance and language shift: Focus on the Malaysian Chinese community. Journal of Multilingual and Multicultural Development, 32(6), 577-591.

Wazir Jahan Karim (2001). Minorities of the minority: Language death and patterns of cultural extinction. In Wazir Jahan Karim \& Razha Rashid (Eds.), Minority cultures of peninsular Malaysia: Survival of indigenous heritage (pp. 69-80). Penang, Malaysia: The Academy of Social Sciences. 